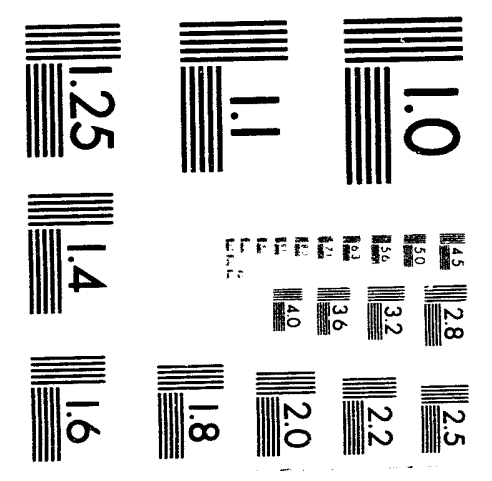



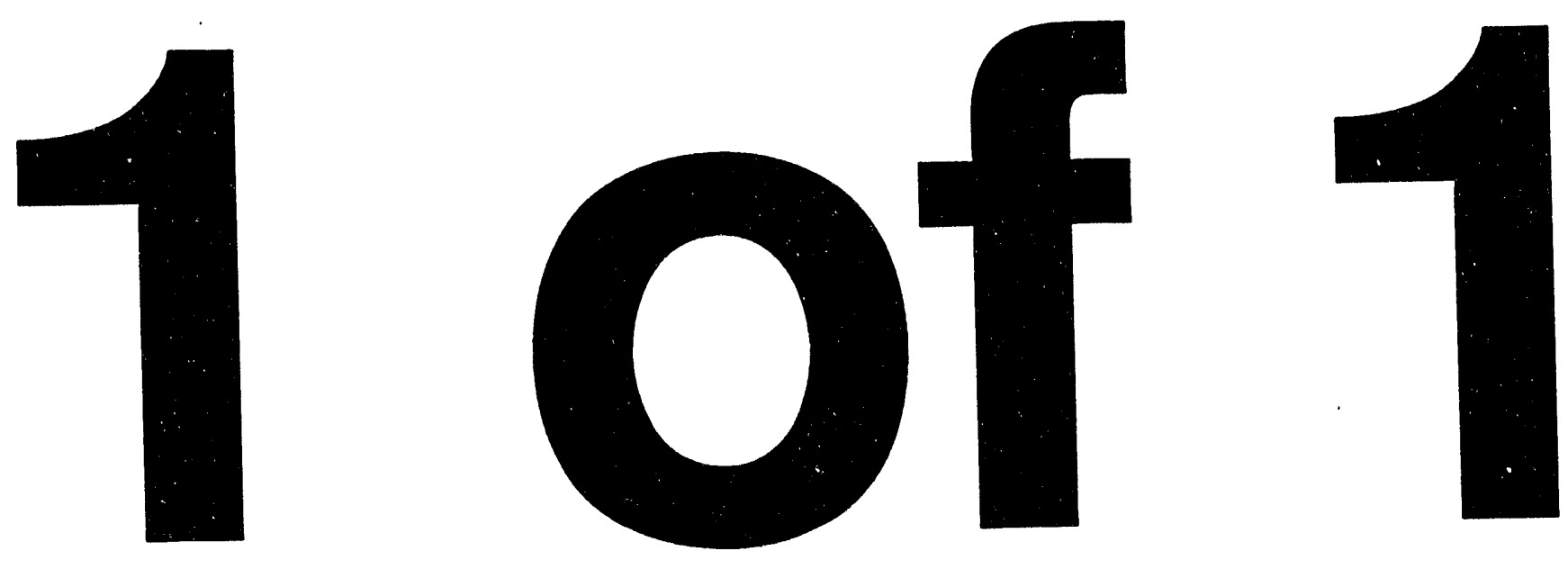


\section{Tank 241-C-103 Vapor and Gas Sampling \\ Data Quality Objectives}

J. W. Osborne

J. L. Huckaby

T. P. Rudolph

E. R. Hewitt

Westinghouse Hanford Company

D. D. Mahlum

J. Y. Young

C. M. Anderson

Pacific Northwest Laboratory

Date Published

February 1994

Prepared for the U.S. Department of Energy Office of Environmental Restoration and

Waste Management

\section{(2) Westinghouse

Hanford Operations and Engineering Contractor fior the

U.S. Department of Energy under Contract DE-AC06-87RL10930

$$
\begin{aligned}
& 5191 \\
& \text { a) } 1
\end{aligned}
$$




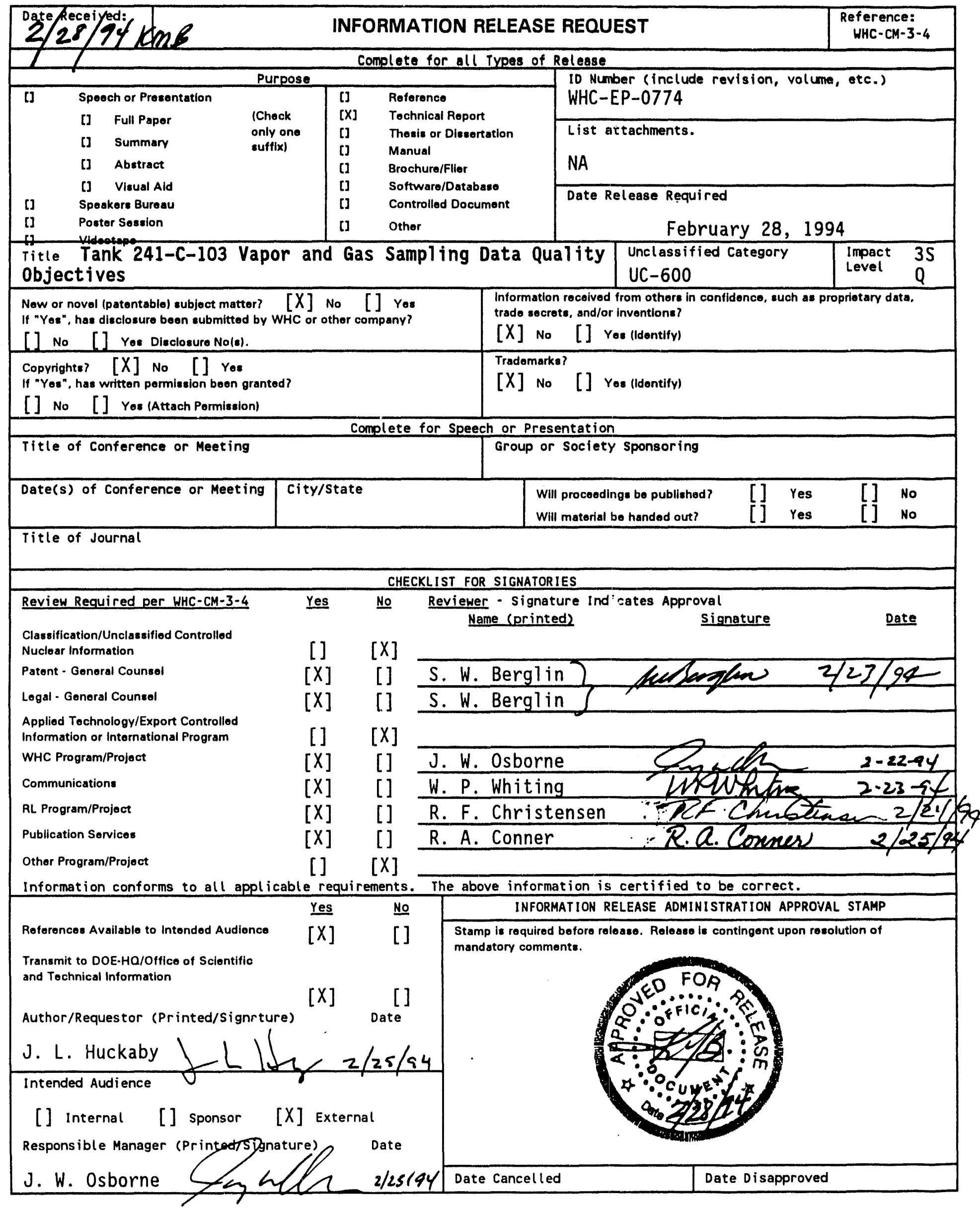




\section{TABLE OF CONTENTS}

EXECUTIVE SUMMARY $\ldots \ldots \ldots \ldots \ldots \ldots \ldots \ldots$ vi

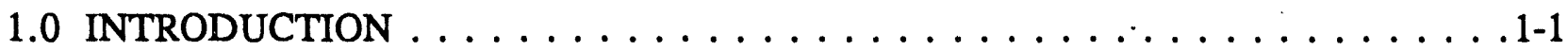

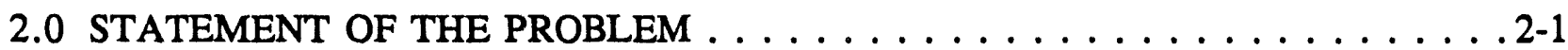

2.1 BACKGROUND ON C-103 . . . . . . . . . . . . . 2-1

2.2 THE FLAMMABILITY PROBLEM $\ldots \ldots \ldots \ldots \ldots \ldots \ldots \ldots . \ldots \ldots$

2.2.1 Approach to Resolving the Flammability Problem $\ldots \ldots \ldots \ldots .2-2$

2.3 THE HUMAN HEALTH PROBLEM $\ldots \ldots \ldots \ldots \ldots \ldots \ldots . . \ldots . . \ldots$

2.3.1 Approach to Addressing the Human Health Problem . . . . . . . 2-3

2.4 PARTICIPANTS IN DQO DEVELOPMENT $\ldots \ldots \ldots \ldots \ldots \ldots \ldots .4$

3.0 KEY DECISIONS, REQUIRED INPUTS AND BOUNDARIES $\ldots \ldots \ldots \ldots$. . . . .

3.1 DECISIONS TO BE MADE $\ldots \ldots \ldots \ldots \ldots \ldots \ldots \ldots \ldots \ldots$

$3.1: 1$ Flammability Decision $\ldots \ldots \ldots \ldots \ldots \ldots \ldots \ldots \ldots \ldots \ldots \ldots$

3.1.2 Toxicity Decision Statement . . . . . . . . . . . . . 3-1

3.2 INPUTS TO THE DECISION $\ldots \ldots \ldots \ldots \ldots \ldots \ldots \ldots \ldots . \ldots \ldots$. $\ldots \ldots \ldots$

3.2.1 Flammability Decision Inputs $\ldots \ldots \ldots \ldots \ldots \ldots \ldots . . \ldots \ldots$ 3-2

3.2.2 Toxicity Decision Inputs . . . . . . . . . . . . . . 3-2

3.2.3 Development of Consensus Exposure Standards . . . . . . . . 3-2

3.3 DEFINE THE BOUNDARIES OF THE STUDY . . . . . . . . . . . 3-4

3.3.1 Spatial and Temporal Boundaries for the Initial Flammability

Determination . . . . . . . . . . . . . . . . . . . 3-4

3.3.2 Spatial and Temporal Boundaries for the Toxicity Decision . . . . . 3-4

4.0 DECISION RULES $\ldots \ldots \ldots \ldots \ldots \ldots \ldots \ldots \ldots \ldots \ldots \ldots \ldots \ldots . \ldots \ldots \ldots$

4.1 FLAMMABILITY DECISION RULE $\ldots \ldots \ldots \ldots \ldots \ldots \ldots \ldots$. . . . $\ldots \ldots$

4.2 TOXICITY DECISION RULE $\ldots \ldots \ldots \ldots \ldots \ldots \ldots \ldots \ldots$. . . . . . . . .

5.0 LIMITS ON DECISION ERRORS $\ldots \ldots \ldots \ldots \ldots \ldots \ldots \ldots \ldots$. . . . . . . . . .

5.1 DEVELOPMENT OF FLAMMABILITY DECISION ERROR LIMITS . . 5-1

5.1 .1 Desired Performance Curve Inputs . . . . . . . . . . . 5-1

5.2 DEVELOPMENT OF TOXICITY DECISION ERROR LIMITS $\ldots \ldots \ldots .5-2$

5.2.1 Desired Performance Curve Inputs . . . . . . . . . . . 5-3

6.0 SAMPLING DESIGNS FOR OBTAINING DATA $\ldots \ldots \ldots \ldots$ 6-1

6.1 STATISTICAL TERMINOLOGY . . . . . . . . . . . . . . 6-1

6.2 SEMIVOLATILE ORGANIC VAPOR AND AEROSOL SAMPLING $\ldots .66-2$

6.2 .1 Design Assumptions $\ldots \ldots \ldots \ldots \ldots \ldots \ldots$. . . . . . . . . .

6.2.2 Select the Appropriate Statistical Test . . . . . . . . . . 6-2

6.2 .3 Obtain Pertinent Estimates of Uncertainty . . . . . . . . 6-3

6.2.4 Power Analysis of the LFL Decision Rule . . . . . . . . . . 6-3 


\section{TABLE OF CONTENTS (continued)}

6.3 HEATED SINGLE TUBE SAMPLE JOB $\ldots \ldots \ldots \ldots \ldots \ldots \ldots$. . . . . . .

6.3.1 Design Assumptions . . . . . . . . . . . . . . . . 6-8

6.3.2 Select the Appropriate Statistical Test . . . . . . . . . . . . . 6-8

6.3.3 Obtain Pertinent Estimates of Uncertainty . . . . . . . . . . 6-9

6.3 .4 Power Analysis . . . . . . . . . . . . . . . . .6-9

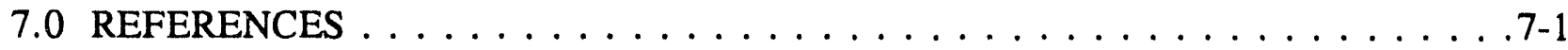

\section{LIST OF TABLES}

2-1 Participants in DQO Development Effort . . . . . . . . . . . . 2-5

5-1 Desired Performance for the Flammability Decision . . . . . . . . . . . . . 5-2

5-2 Desired Performance for the Toxicity Decision: Carcinogenic, Teratogenic or Mutagenic Constituents . . . . . . . . . . . . . . . . . . .5-3

5-3 Desired Performance for the Toxicity Decision: Systemic Toxicant Constituents . 5-3

5-4 Desired Performance for the Toxicity Decision: Irritant Constituents . . . . . . . 5-4

6-1 Desired and Achieved Power Given a Standard Deviation of $0.02 \ldots \ldots$. . . . . 6-6

6-2 Desired and Achieved Power Given a Standard Deviation of $0.03 \ldots$. . . . . 6-7

6-3 Desired and Achieved Power Given a Standard Deviation of $0.04 \ldots$. . . . . . 6-7

6-4 Desired and Achieved Power Given a Standard Deviation of $0.05 \ldots$. . . . . 6-7

6-5 Desired and Achieved Power Given a Standard Deviation of $0.06 \ldots$. . . . . 6-7 


\section{LIST OF ACRONYMS}

ACGIH

AIHA

CES

DOE

DOE-RL

DQOs

$\mathrm{FC}_{\mathrm{NPH}}$

LFL

NPH

OSHA

PEL

PNL

REL

TLV

TRP

USEPA

USQ

WEEL

WHC
American Conference of Governmental Industrial Hygienists American Industrial Hygiene Association

Consensus exposure standard

U. S. Department of Energy

U. S. Department of Energy - Richland Operations Office

Data quality objectives

Fuel content due to normal paraffinic hydrocarbons

Lower flammability limit

Normal paraffinic hydrocarbons

Occupational Safety and Health Administration

Permissible exposure limit

Pacific Northwest Laboratory

Recommended exposure limit

Threshold limit value

Toxicology review panel

U.S. Environmental Protection Agency

Unreviewed safety question

Workplace environmental exposure levels

Westinghouse Hanford Company 


\title{
TANK 241-C-103 VAPOR AND GAS SAMPLING DATA QUALITY OBJECTIVES
}

\author{
EXECUTIVE SUMMARY
}

Data Quality Objectives (DQOs) for tank 241-C-103 vapor and gas sampling were developed in a series of five facilitated meetings, using the most recent U. S. Environmental Protection Agency (USEPA) DQO guidelines. These meetings elicited DQOs for two vapor problem areas: flammability and toxicity. What follows is a summary of the outputs of the planning team for each of the seven steps of the DQO process. More details regarding the rationale for each of the DQO planning outputs are contained in the DQO document that follows this summary.

\section{Step 1. Problem Statement}

Two problems were addressed: Potential flammability of gases, vapors, and an aerosol in tank 241-C-103 (hereafter identified as C-103) and potential worker health and safety hazards associated with the toxicity of constituents in C-103. Previous work indicated the potential presence of a fog in the tank, and the fuel content of the tank gases, vapors, and aerosol may be too high to permit work in the tank. Ten reports of adverse health effects associated with vapor exposures near C-103 or in $\mathrm{C}$-Farm have been made by workers. Reported symptoms include headaches, burning sensations in nose and throat, nausea, and impaired pulmonary function.

Data are needed to identify and quantify constituents of the C-103 headspace to address potential vapor toxicity. When the compounds of toxicological interest in the tank headspace are identified, industrial hygienists can assess "worst-case" worker exposure levels and focus their industrial hygiene monitoring strategy on these target compounds. Final recommendations on the required level of personal protective equipment will be based on the worker breathing zone levels of these chemicals.

Resolution of these problems involves a sequence of sampling events. The first sampling event assesses flammability of the semivolatile organic vapor and aerosol content of the headspace. If the flammability assessment results are acceptable, special vapor sampling equipment will be installed in the tank. This equipment will be used in subsequent sampling events to: 1) establish concentrations of $\mathrm{a}^{\text {" }}$ flammable headspace constituents; 2) identify compounds of toxicological concern; 3) establish appropriate sampling and analytical methods; and 4) quantify compounds of toxicological concern. 


\section{Step 2. Decision Statements}

\section{A. Flammability Decision}

If the total fuel content of the headspace is $\geq 20 \%$ of the lower flammability limit (LFL), then work must stop until authorized by management:

\section{B. Toxicity Decision}

If any compounds with toxicological properties exceed their allowed levels inside the tank headspace, then advise Health and Safety. Allowed levels are:

- $10 \%$ of the appropriate CES concentration for known or suspected human carcinogens, teratogens and mutagens

- $50 \%$ of the appropriate consensus exposure standard (CES) concentration for non-carcinogens, non-teratogens and non-mutagens.

Step 3. Inputs to the Decision

- Identification and quantification of flammable constituents in the headspace

- Temperature of the headspace

- Identification and quantification of compounds of toxicological importance

- Understanding of the toxicological effects of these compounds and the CES for each constituent of concern.

Step 4. Boundaries of the Study

The spatial boundaries of the vapor and gas sampling events are defined by the waste surface, walls and dome of the waste tank itself. Sampling events will be scheduled to address diurnal, seasonal, and long-term changes in the vapor and gas concentrations.

\section{Step 5. Decirion Rules}

\section{A. Flammability Decision Rule}

If the total fuel content of the headspace equals or exceeds $20 \%$ of the LFL for the observed mixture, then stop work and take appropriate actions before resuming sampling or other work on the tank. 
Initially, the fuel content of the headspace will be estimated by assuming that the normal paraffinic hydrocarbons (NPH) in the $\mathrm{C}_{11} \mathrm{H}_{24}$ to $\mathrm{C}_{15} \mathrm{H}_{32}$ range represent at least $66 \%$ of the total fuel. Therefore, if $1.5 \times$ the sum of NPH concentrations is greater than or equal to the temperature-corrected LFL for NPH, then intrusive work must stop, and the responsible safety organization must be notified.

\section{B. Toxicity Decision Rule}

The DQO team established decision rules organizing potentially toxic substances by type to include carcinogens, teratogens and mutagens, systemic toxins, and irritants. The toxicity decision rules were specified as follows:

- If the average concentration of any known or suspected human carcinogen, teratogen, or mutagen in a tank headspace is greater than one-tenth of its CES, then advise the industrial hygiene group that a compound(s) of toxicological concern is present in the tank headspace so that appropriate worker protection actions can be taken.

- If the average concentration of any systemic toxin in a tank headspace is greater than one-half its CES, then advise the industrial hygiene group that a compound(s) of toxicological concern is present in the tank headspace so that appropriate worker protection actions can be taken.

- If the average concentration of any irritants in a tank headspace is greater than one-half of its CES, then advise the industrial hygiene group that a compound(s) of toxicological concern is present in the tank headspace so that appropriate worker protection actions can be taken.

Step 6. Limits on Decision Errors

\section{A. Flammability Decision Errors}

One type of decision error would occur if data incorrectly indicate $\mathrm{LFL}_{\mathrm{MIx}} \geq 20 \%$.

\section{Consequences:}

- Unnecessary stop work resulting in schedule delays and significant costs

- Safety review and associated costৎ and schedule delays

- Eventual credibility loss

- $\quad$ Bad press to all parties

- Critical path slowdown; cost implications on overall program

- More complex analysis of LFL must be conducted. 
A second kind of decision error would occur if data incorrectly indicate $\mathrm{LFL}_{\mathrm{MIX}}<20 \%$.

Consequences:

- $\quad$ Proceed with sampling with the potential for an ignition; THIS IS OF MAJOR CONCERN -- large cost, health, and safety implications

- Eventual credibility loss

- Potential to continue use of unacceptable operating techniques.

\section{B. Toxicity Decision Errors}

One type of decision error would occur if data incorrectly indicate that the prescribed limits have been exceeded, when in fact they haven't.

\section{Consequences:}

- Needless control measures

- Productivity loss

- Eventual loss of creditability

- Westinghouse Hanford Company (WHC) impacts

- Cost of resampling, etc.

A second type of decision error would occur if data incorrectly indicate that the prescribed limits have not been exceeded, when in fact they have.

Consequences:

- $\quad$ Potential illness (worker impact)

- Eventual creditability loss

- WHC impacts

- Liability to WHC/U. S. Department of Energy (DOE)

- Eventual cost of resampling, etc.

The relative consequence of the second type of decision error (failure to find a true problem) was determined to be roughly 2.5 times greater than the other type of decision error. 
Step 7. Develop and Optimize the Design for Collecting Data

The WHC strategy to resolve the flammability and toxicity issues was approved by DOE reviewers prior to initiation of this DQO (O'Dell 1993, Christensen 1993). The DQO process was consequently limited by constraints imposed by these designs. Therefore, Step 7 addresses the expected performance of the flammability assessment sampling, and the proposed sampling strategy for determining headspace vapor and gas toxicity.

In conclusion, the DQO process for $\mathrm{C}-103$ vapor sampling has been a retrospective re-examination of the strategy to characterize the headspace of this tank. It has proven beneficial because it has offered the program manager an opportunity to reassess the goals and objectives of the experimental design. The prior planning and strategy proved adequate to meet program objectives; this re-affirmation of the "correctness" of the approach and ultimate data output enhances overail confidence in the data and ultimately in the safety decisions made from these data. 


\section{TANK 241-C-103 VAPOR AND GAS SAMPLING DATA QUALITY OBJECTIVES}

\subsection{INTRODUCTION}

The DQO process was designed to facilitate planning of data-collection efforts. The ideal way to use the process is to structure the thinking that goes on immediately following the recognition that data will be required to resolve a problem. To help focus the planning exercise, the DQO process starts by describing the problem. It then leads a planning team through a structured set of steps which build on one another to describe why data are needed, from where and when data should be collected, how data will be summarized and used in support of a decision, and how much uncertainty can be tolerated in that decision. The DQOs are the products of each step of the process and provide essential input to the statistically based sampling and analysis plan designed to generate the right amount and quality of data for decision making.

The DQO process was applied to vapor problems associated with tank 241-C-103, referred to hereafter as C-103, after most of the project planning had already taken place. In fact, the approach for sampling, methods, number and location of samples had already been determined and specified in sample job descriptions, engineering work plans, and operating procedures. Given these circumstances, the primary function of the DQO process was to elicit and document the planning work that had occurred, and to uncover any missing elements in the previous planning efforts. By specifying DQOs, an important set of criteria are documented that enable future users of the data to determine the data's adequacy and limitations. In addition, because most of the sampling would not occur until after the DQOs were completed, minor changes could be incorporated to improve the vapor sampling effort.

DQOs were elicited through a series of five half-day meetings. The facilitators led the planning team through the DQO steps as described in guidance issued by the USEPA (1993). Just prior to completing this DQO process, WHC and Pacific Northwest Laboratory (PNL) issued a draft set of DQO process guidelines tailored to the Tank Waste Remediation (TWRS) Program (Michael et al. 1993).

At the first meeting, expectations for this DQO process were discussed to provide an internal measure of success for all participants. The group's expectations included:

- Documentation of goals, strategies, and previously established methodologies

- Justification for approach: DOE and WHC confirmation that we are doing the "right thing"

- Initiation of a stopping rule to determine when enough samples/analyses have been obtained

- Generation of a guidance document for preparing sampling and analysis plans

- $\quad$ Allaying fears of the oversight groups

- Facilitating preparations for upcoming sampling events. 
This document reports the specifications developed by the planning team. Every effort has been made to capture the final products agreed on by this team. Historical development of the thoughts contained herein can be gleaned from the series of meeting notes kept by the facilitator and reviewed by the program manager. In order to be as objective as possible in developing the various process outputs, the DQO process was, for the most part, applied as if the program had not already been designed. However; at a number of times the decision maker and key engineer felt constrained by what was already in place and determined that these constraints should focus the thinking of the group. 


\subsection{STATEMENT OF THE PROBLEM}

\subsection{BACKGROUND ON C-103}

For a period of 33 years (1946-1979), C-103 received about 30 types of waste from various sources, both directly and as a receiving tank in a tank cascade (Jungfleisch 1987, Carothers 1988). According to Jungfleisch, the wastes added to C-103 included wastes generated from four primary recovery processes, two secondary recovery processes, evaporators, in-tank solidification processes, semi-works operations, decontamination processes, N Reactor, PNL, and both in-process and in-tank waste scavenging. C-103 was also an accumulator tank for metal waste (before processing for uranium recovery) from other tanks and for supernatant (before processing for cesium recovery) from other tanks.

In the September 22, 1988 Carothers memorandum, it was noted that knowledge of the exact composition of the various materials added to $\mathrm{C}-103$ from decontamination, $\mathrm{N}$ Reactor waste and PNL waste was lacking because of the then-proprietary nature of those operations. However, it is likely that the tank contains tributyl phosphate, the $n-\mathrm{C}_{11} \mathrm{H}_{24}$ through $n-\mathrm{C}_{15} \mathrm{H}_{32} \mathrm{NPH}$, and various radiation-induced degradation products. After July 1979, no wastes were transferred into or out of $\mathrm{C}-103$. At present, $\mathrm{C}-103$ is designated as an organic-bearing tank and is on the "Watch List" (Strachan et al. 1993). It was estimated by Hanlon in 1994 that the tank contains 234,732 L (62,000 gal) of sludge and 503,538 L $(133,000 \mathrm{gal})$ of supernatant liquids. From a December 1993 sampling event, it is now known that the floating layer of organic liquid is between 3.8 to $5.1 \mathrm{~cm}$ (1.5 to $2.0 \mathrm{in}$.) thick.

\subsection{THE FLAMMABIITY PROBLEM}

The existence of a floating layer of organic liquid in C-103 was declared to be an unreviewed safety question (USQ) in September 1992. At issue are a liquid pool fire's potential effects on the tank and the environment. All non-essential field work involving this tank was suspended, and permission to conduct operations designed to resolve the USQ was sought. The DOE granted permission to perform the specific field work on the tank, as described in Environmental Assessment: Tank 241-C-103 Organic Vapor and Liquid Characterization and Supporting Activities, Hanford Site, Richland, Washington (Engelmann 1993). That document states in Appendix A that the flammability of the C-103 headspace is to be measured and determined to be below $25 \%$ of the LFL before other work to characterize the tank contents may proceed

It has been postulated that the headspace of C-103 may contain an aerosol of organic liquid droplets (Trent 1990), and there is some evidence to support this (Huckaby and Estey 1992). The existence of an organic aerosol could significantly increase the amount of fuel in the headspace, and in principle could result in a flammable condition. Unfortunately, the instruments normally used to evaluate the flammability of gases at the Hanford Site, 
combustible gas meters, cannot properly account for fuel present as an aerosol. Hence, it was decided that an alternative method was needed for measuring the C-103 headspace flammability.

\subsubsection{Approach to Resolving the Flammability Problem}

Precise determination of the flammability of the C-103 headspace requires knowledge of the flammable vapor and gas concentrations, as well as knowledge of the particle size distribution, number, density, chemical identity, and distribution of aerosol within the headspace. Reasonable arguments have been made that suggest the fuel content of the headspace is much less than $25 \%$ of the LFL (Huckaby and Estey 1992), and that complete characterization of the aerosol is unnecessary.

A methodology for measuring the C-103 headspace flammability was developed between September and December, 1992, by a team of scientists and engineers working for the Tank Vapor Issue Resolution Program. This methodology uses the conservatively safe assumption that any fuel present as liquid aerosol droplets will burn as though it were a vapor, and thereby presupposes that it is unnecessary to characterize the aerosol. Equipment needed to carry out this methodology was designed, fabricated, and tested in early 1993. The engineering work plan (Huckaby 1993) provides justification and details of the first sampling event.

An initial, limited sampling event will be used to estimate the concentration of NPH in the tank headspace. This sampling event (referred to as sample job 6), will use Occupational Safety and Health Administration (OSHA) versatile sampler traps to collect the semivolatile organic vapors and any aerosol from within the C-103 headspace. Analyses of these samples, to be performed by the PNL Chemistry Group, will target NPH but will also address identification and quantification of other semivolatile organic compounds, such as tributyl phosphate. The total fuel content of the headspace will then be calculated assuming the observed concentration of NPH represents two-thirds of the total fuel, as has been indicated by earlier analysis of vapor samples from C-103. Assuming that the fuel concentration calculated from this initial sampling event is below $20 \%$ of the LFL, as required by operational guidelines, more sophisticated sampling techniques will be used to collect representative samples from the headspace so that the contributions of all flammable species in the headspace (i.e., hydrogen, volatile and semivolatile organic compounds) can be determined, rather than relying solely on the determination of NPH and extrapolating this value to the rest of the flammable constituents.

The initial flammability test, which estimates the headspace fuel concentration using only the concentration of $\mathrm{NPH}$, is based on several assumptions. The validity oi these assumptions will be addressed in subsequent sampling events. The critical assumption that the NPH represents two-thirds of the fuel in the headspace will be tested by the next scheduled sampling event, sample job $6 \mathrm{~B}$, when the more elaborate sampling equipment 
needed to collect representative samples is installed. The assumption that the headspace flammability does not change significantly with diurnal or seasonal cycles will also be addressed in sample Job 7 and later sample jobs.

This methodology for measuring the C-103 headspace flammability and the assumptions on which it is based have been discussed with aerosol experts at Sandia National Laboratory and PNL, and with flammability experts at Hazards Research Corporation ${ }^{1}$. It has been reviewed by the Waste Management External Advisory Committee, and presented to the Vapors and Conduct of Operations Subpanel of the Tank Advisory Panel. Official acceptance of the approach has been granted by C. O'Dell, DOE (O'Dell 1993), and R. F. Christensen, Corrective Actions Branch, DOE - Richland Field Office (DOE-RL) (Christensen 1993).

\subsection{THE HUMAN HEALTH PROBLEM}

The major issue which must be resolved is: Are tank farm workers being exposed to potentially hazardous chemical constituents from C-103 at levels which exceed those established as safe for workers?

A number of people have reported adverse health effects, including headaches, burning sensations in the nose and throat, nausea, and impaired pulmonary function, while working around high-level waste tanks at the Hanford Site. As indicated in the 1993 Program Plan for the Resolution of Tank Vapor Issues (Osborne 1992), musty and foul odors, inctuding the smell of ammonia, have been reported emanating from several singleshell tanks. During the period between July 1987 and May 1992, 16 complaints of exposures to odors were reported, involving 27 workers. Ten of these occurrences, involving 18 workers, were associated with the 241-C tank farm, and C-103 in particular was implicated in 6 of the reported occurrences.

\subsubsection{Approach to Addressing the Human Health Problem}

The reports of illness experienced by people working near C-103 have led to a need to deternine if the symptoms were related to emissions coming from this tank. This determination involves a number of steps, including:

1) Analysis of constituents in the tank headspace to establish the maximum concentrations of constituents released by the tank

2) Analysis of volatile constituents that are released through the high-efficiency particulate air filter on the tank exhaust port

3) Determination of major routes and levels of fugitive emissions from the tank

${ }^{1}$ Hazards Research Corporation, 200 Valley Road, Suite 301, Mt. Arlington, New Jersey, 07856. 
4) Evaluation of the toxicological potential (including exposure potential) of the headspace constituents and the materials released from the tank

5) Area monitoring

6) Breathing zone monitoring.

This DQO process will focus only on the in-tank measurements to identify constituents of potential concern to worker health and safety (item 1 above).

When sufficient data have been obtained for the above areas, it will be possible to determine what control or monitoring measures, if any, are necessary. In the interim, the Environmental Safety and Quality Assurance Office, WHC, has adopted the American Industrial Hygiene Association (AIHA) sampling protocols to monitor personnel exposure to tank farm vapors. The results of sampling will be used to resolve worker protection in and around the tank farm area. As in-tank analytes of toxicological interest are identified, the industrial hygiene monitoring strategy will be reassessed.

\subsection{PARTICIPANTS IN DQO DEVELOPMENT}

Implementation of the DQO process for $\mathrm{C}-103$ vapor issues involved management and technical staff spanning a wide range of disciplines including health and safety experts, engineers, chemists, statisticians, and DQO facilitators. The following table includes all those who actively participated in the four DQO development meetings. On completion of this document, comments will be sought by other stakeholders including DOE, USEPA, and the State of Washington Department of Ecology with the goal of obtaining concurrence from all important data users. Given that the basic approach and design were formally approved before initiation of this DQO process, concurrence by the planning team is expected. The important stakeholders have been kept informed of this program, before and during the development of these DQOs. 
Table 2-1. Participants in DQO Development Effort.

\begin{tabular}{|l|l|}
\hline WHC: & PNL: \\
J. W. Osborne, Manager, Tank Vapor & J. Y. Young, Industrial Hygienist \\
Issue Resolution Program & D. D. Mahlum, Toxicologist \\
J. L. Huckaby, Lead Engineer, Tank & C. M. Anderson, Statistician \\
Vapor Issue Resolution Program & J. L. Scott, DQO Meeting Coordinator \\
T. P. Rudolph, Health and Safety & P. J. Turner, DQO Meeting Coordinator \\
$\begin{array}{l}\text { E. R. Hewett, Health and Safety } \\
\text { P. M. Morant, Hanford Analytical Services }\end{array}$ & R. B. Lucke, Chemist \\
Northwest Instrument Systems, Inc.: & Neptune and Company: \\
M. S. Story & D. I. Michael, DQO Facilitator \\
Mactec (DOE-RL): & D. Neptune, DQO Facilitator \\
K. S. Redus, Observer & \\
M. Miller, Observer &
\end{tabular}


This page is intentionally left blank. 


\subsection{KEY DECISIONS, REQUIRED INPUTS AND BOUNDARIES}

\subsection{DECISIONS TO BE MADE}

Two key decisions will be made based on the data collected. However, these decisions will be revisited after a series of sampling events designed to reduce uncertainty and test assumptions implicit to the design.

\subsubsection{Flammability Decision}

A determination of tank headspace flammability will be made after each of several planned sampling jobs. Fewer assumptions will be needed after each successive sampling result. For example, the first decision will be based primarily on NPH measurement and the assumed relative contribution of NPH to the headspace flammability. An assumption will be made that constituents are homogeneously distributed within the headspace and that there is no temporal variability. Subsequent sample jobs are expected to provide more complete data on the flammable constituents, first at one time and location within the tank, then at several depths within the headspace, and finally by season.

If the total fuel content of the vapors and aerosol contained in C-103 is $\geq 20 \%$ of the LFL, then stop work and take one of the following actions:

- Attempt to lower the fuel content of the tank below $20 \%$ of the LFL so that work may continue

- Do a comprehensive review of sampling equipment and modify for operating in a flammable environment

- Reassess the flammability by re-analyzing assumptions and data, and/or resampling.

If the total fuel content is < $20 \%$ of the LFL based on a set of conservative assumptions, then proceed with subsequent sample jobs to address all flammable constituents.

\subsubsection{Toxicity Decision Statement}

If any compounds with toxicological properties exceed their allowahle levels inside the tank, then advise Health and Safety that compounds of toxicological concern are present in the tank headspace. The allowable levels are:

- $10 \%$ of the appropriate CES concentration for known or suspected human carcinogens, teratogens and mutagens 
- 50\% of the appropriate CES concentration for non-carcinogens, non-teratogens and non-mutagens.

A CES is generally defined as the most stringent of known regulatory or recommended toxicological values including the threshold limit values (TLV), permissible exposure limits (PEL), and recommended exposure limits (REL). For those constituents with unspecified toxicological values, a professional panel will be responsible for development of a CES.

\subsection{INPUTS TO THE DECISION}

\subsubsection{Flammability Decision Inputs}

The planning team developed an initial lisi of data needs associated with the key flammability decision listed above. As each subsequent step was considered, especially as decision rules were developed, additional data needs were identified and captured here. The data needs were determined to be:

- Identification of all flammable constituents in the headspace

- Estimates of the concentrations of each flammable constituent in the headspace

- Temperature of the headspace

- Estimates of the relative amount of flammable constituents in the vapor and aerosol fractions from analysis of various sections of the sorbent tubes.

\subsubsection{Toxicity Decision Inputs}

The following data needs are associated with the C-103 toxicology decision:

- Identification of chemical compounds of toxicological importance in the tank headspace

- Concentrations of these compounds in the headspace

- Understanding of the toxicological effects of these compounds and the CES for each constituent of concern.

\subsubsection{Development of Consensus Exposure Standards}

CESs will be generated for each compound of potential toxicological interest detected in the headspace. Industrial hygienists have several sources of information for exposure standards against which sampling results may be compared in order to determine whether or not an unacceptable exposure condition exists. A primary source is the American Conference of Governmental Industrial Hygienists (ACGIH) recommended TLVs with some 700 chemicals listed. For compliance purposes, the PELs listed in Subpart $\mathrm{Z}$ of the OSHA regulations are used (29 CFR 1910.1000). NIOSH has developed RELs based on recent research and new information about the chemicals, and these RELs are intended for adoption 
into OSHA regulations. The AIHA has also developed Workplace Environmental Exposure Level (WEEL) guides listing chemicals for which no current exposure guidelines have been established by other organizations.

In selecting appropriate exposure limits for the chemical constituents in the C-103 headspace, the toxicology review panel (TRP) will first consult the ACGIH TLVs booklet, the OSHA PEL tables, the National Institute of Safety and Health list of RELs, and the AIHA WEELs. The most stringent standard will be used.

If a chemical does not have published exposure standards, the TRP will provide a best estimate of the level of acceptable exposure to the chemical. Derivation of a CES must rely heavily on professional judgement. It may involve an initial literature search in various databases for available information on the chemical. Current databases may include:

- Registry of Toxic Effects of Chemical Substances (RTECS)

- National Air Toxics Information Clearinghouse (NATICH)

- Integrated Risk Information System (IRIS)

- Gene-Tox Database through the National Library of Medicine

- MEDLINE

- ETIC

- TOXLINE

- CHEMLINE

- Monographs by the International Agency for Research on Cancer (IARC)

- Others as appropriate.

Evaluation of health effects may require information about the chemical's (or similar analog's) adverse effects, thresholds, possible evidence of carcinogenicity, genotoxicity, developmental toxicity, reproductive toxicity, systemic toxicity, and skin/eye irritation. The no-observable-adverse-effect-level, if available, may be useful for animal-to-human extrapolation. Another numerical value for consideration is the maximum tolerated dose. Generally, factors considered in the toxicity evaluation of a chemical may also include its pharmacokinetic properties, effects on target organs, metabolism (biochemical reaction and transformation), and the rate of absorption and distribution. For example, when considering route-to-route extrapolation, the limitations of extrapolation are clearly apparent and one must account for:

- Difference in absorption efficiency

- Difference in systemic effects

- Occurrence of critical toxic effects at portal of entry

- First-pass effects that may resuit in either bioactivation or detoxification of chemical prior to reaching the target organ

- Variations in the time course of target organ concentrations of toxicologically active species. 
In addition, other factors may include known specific chemical interactions, severity of effects, and other significant effects. The TRP will have to make various assumptions, based on professional judgement, to understand toxicological effects for chemicals with little or no known toxicity information. To support the tank farm vapor program, the TRP will apply methods that are scientifically defensible, short of conducting research, to formulate a recommended consensus exposure standard for those chemicals. Insofar as possible, the TRP will employ the same approach to evaluate new chemicals that AIHA uses in establishing WEELs.

\subsection{DEFINE THE BOUNDARIES OF THE STUDY}

\subsubsection{Spatial and Temporal Boundaries for the Initial Flammability Determination}

The initial flammability decision is spatially bounded by the internal dimensions of the tank above the level of waste in the tank. This volume is known as the "headspace" of the tank. Due to tank access restrictions that make most of the tank headspace inaccessible, the initial flammability decision will be based on samples taken from a single location $2.13 \mathrm{~m}$ $(7 \mathrm{ft})$ from the side of the tank and $1.06 \mathrm{~m}(3.5 \mathrm{ft})$ above the waste surface. The highest aerosol concentrations are thought to be near the liquid surface (Huckaby and Estey 1992). In later sampling events, samples from three different heights representing approximately equal volumes of the headspace will be collected.

Concentrations of flammable constituents are not expected to fluctuate greatly. There is an approximate $5^{\circ} \mathrm{C}$ fluctuation in tank temperature associated with the seasons.

\subsubsection{Spatial and Temporal Boundaries for the Toxicity Decision}

A decision concerning the toxicity of $\mathrm{C}-103$ vapors and gases will be made for the tank headspace. Data to support this decision will be collected from three levels in the tank unless it is determined that the headspace is homogeneous. Due to the restrictions that make most of the tank headspace inaccessible, samples will be taken from a single tank riser that is available for entry.

Tank temperatures vary slightly by season. Concentrations of toxic compounds that could potentially be emitted from the tank are expected to fluctuate with these temperature changes. To capture the expected variability, a temporal boundary has been established. Decisions will be made for the warmest and coolest seasonal conditions. The warmest tank temperatures are known to occur during the fall, due to heating of the ground above the tank during the preceding summer months. 


\subsection{DECISION RULES}

The specification of decision rules for each of the identified decisions is a critical step in the DQO process. The decision rule combines the earlier statements into a single statement which specifies how data will be used to make each decision. Even though a sophisticated sampling and analysis strategy had been developed prior to developing DQOs, this strategy had not been satisfactorily documented.

\subsection{FLAMMABILITY DECISION RULE}

The planning team reviewed the rules for calculating LFLs of a mixture specified in the engineering work plan. After much discussion, the team arrived at a generic decision rule, as well as a specific decision rule based on the assumption that NPH constitutes $66 \%$ of the total fuel content of the headspace. These rules are as follows:

Generic:

If the total fuel content of the headspace (estimated from the sum of the mean concentration of each observed fuel constituent in the vapor space) equals or exceeds $20 \%$ of the LFL for the observed mixture, then stop work (see statement of the decision for the action options). This rule will apply to the second and third sample jobs, where valid estimates of the concentration of all major fuel constituents should be generated.

NPH Specific:

If the fuel content of the NPH $\left(\mathrm{FC}_{\mathrm{FPH}}\right)$ in the headspace $\times 1.5$ is less than $20 \%$ of the LFL for the observed mixture ( $\left(\mathrm{LL}_{\mathrm{MIX}}\right.$ ), then stop work and take appropriate actions before resuming sampling or other work on the tank. Le Chatelier's law (Zabetakis 1965) will be used to calculate $\mathrm{LFL}_{\mathrm{MIX}}$ :

$$
\mathrm{LFL}_{\mathrm{MIX}}=\left(\sum \frac{\mathrm{Y}_{\mathrm{i}}}{\mathrm{LFL}_{\mathrm{i}}}\right)^{-1}
$$

wh ere $Y_{i}$ and $\mathrm{LFL}_{\mathrm{i}}$ are the vapor phase mole fraction and lower flammability limit, respectively, of component $\mathrm{i}$, and the summation is over all the semivolatile NPH. The $\mathrm{LFL}_{\mathrm{i}}$ will be adjusted from their $25^{\circ} \mathrm{C}$ reference temperature to the temperature of the headspace, $\mathrm{T}$, using the following relationship for paraffinic hydrocarbons given by Zabetakis 1965 : 


$$
\operatorname{LFL}\left(\mathrm{T}^{\circ} \mathrm{C}\right)=\operatorname{LFL}\left(25^{\circ} \mathrm{C}\right)\left[1-0.000721\left(\mathrm{~T}-25^{\circ} \mathrm{C}\right)\right]
$$

If there is evidence that $\mathrm{FC}_{\mathrm{NPH}}$ is not at least $66 \%$ of the total fuel content of the headspace, then this decision rule will be revised.

\subsection{TOXICITY DECISION RULE}

The DQO team established decision rules organizing potentially toxic substances by type to include known or suspected human carcinogens, teratogens and mutagens, systemic toxins, and irritants. The toxicity decision rules were specified as follows:

a) If the average concentration of any known or suspected human carcinogen, teratogen, or mutagen in a tank headspace is greater than one-tenth of its CES, then advise the industrial hygiene group that a compound(s) of toxicological concern is present in the tank headspace so that appropriate worker protection actions can be taken.

b) If the average concentration of any systemic toxin in a tank headspace is greater than one-half its CES, then advise the industrial hygiene group that a compound(s) of toxicological concern is present in the tank headspace so that appropriate worker protection actions can be taken.

c) If the average concentration of any irritants in a tank headspace is greater than one-half of its CES, then advise the industrial hygiene group that compound(s) of toxicological concern are present in the tank headspace so that appropriate worker protection actions can be taken.

For known or suspected human carcinogens, teratogens, and mutagens, a 0.1 safety factor is used instead of a 0.5 safety factor for irritants and systemic toxicants. These safety factors are based on current WHC policy. 


\subsection{LIMITS ON DECISION ERRORS}

Limits on decision errors had not been documented before DQOs were developed. The planning team was interested in determining how well their current design for each phase of sampling was expected to perform. Limits on each type of decision error were elicited to provide a criteria against which to measure the expected performance of their designs.

\subsection{DEVELOPMENT OF FLAMMABILITY DECISION ERROR LIMITS}

The process of specifying limits of decision errors begins by identifying each type of potential decision error and discussing the consequences associated with these error types.

One type of decision error would occur if data incorrectly indicate $\mathrm{LFL}_{\mathrm{MIX}} \geq 20 \%$. Consequences:

- Unnecessary stop work resulting in schedule delays and significant costs

- $\quad$ Safety review and associated costs and schedule delays

- $\quad$ Eventual credibility loss

- $\quad$ Bad press to all parties

- Critical path slowdown; cost implications on overall program

- More complex analysis of LFL must be conducted.

A second kind of decision error would occur if data incorrectly indicate $\mathrm{LFL}_{\mathrm{MIX}}<20 \%$.

Consequences:

- $\quad$ Proceed with sampling with the potential for an ignition; THIS IS OF MAJOR CONCERN -- large cost, health, and safety implications

- Eventual credibility loss

- Potential to continue use of unacceptable operating techniques.

\subsubsection{Desired Performance Curve Inputs}

After identifying the decision errors and their associated consequences, the planning team considered a series of potential error scenarios and specified their aversion to these specific potential decision errors by considering the above stated consequences in Table 5-1. 
Table 5-1. Desired Performance for the Flammability Decision.

\begin{tabular}{|c|c|c|}
\hline $\begin{array}{l}\text { Presumed true fraction of the } \\
\text { LFL }\end{array}$ & $\begin{array}{l}\text { Acceptable qualitative } \\
\text { frequency of deciding to } \\
\text { stop work }\end{array}$ & $\begin{array}{l}\text { Acceptable probability of } \\
\text { deciding to stop work }\end{array}$ \\
\hline less than 0.15 & rarely & $\leq 10 \%$ \\
\hline 0.15 to 0.20 & $\begin{array}{l}\text { region of decision } \\
\text { indifference }\end{array}$ & - \\
\hline 0.20 to 0.50 & often & $\geq 90 \%$ \\
\hline more than 0.50 & almost always (tolerable) & $\geq 99 \%$ \\
\hline
\end{tabular}

\subsection{DEVELOPMENT OF TOXICITY DECISION ERROR LIMITS}

One type of decision error would occur if we observe that the CES threshold (10\% of the CES for known or suspected human carcinogens, teratogens and mutagens, and $50 \%$ of the CES for systemic toxicants and irritants) has bsen exceeded, when, in fact, the true threshold has not been exceeded.

Consequences:

- Needless control measures

- Productivity loss

- Eventual loss of creditability

- WHC impacts

- Cost of resampling, etc.

A second type of decision error would occur if data incorrectly indicate that the prescribed limits have not been exceeded, when in fact they have.

Consequences:

- Potential illness (worker impact)

- Eventual creditability loss

- WHC impacts

- Liability to WHC/DOE

- Eventual cost of resampling, etc. 


\subsubsection{Desired Performance Curve Inputs}

Three different sets of constituents were considered independently due to the types of consequences and differences in action levels. Tables 5-2, 5-3, and 5-4 depict the decision error limits established during the DQO development exercise.

Table 5-2. Desired Performance for the Toxicity Decision: Carcinogenic, Teratogenic or Mutagenic Constituents.

\begin{tabular}{|l|l|l|}
\hline $\begin{array}{l}\text { Presumed "true" fraction of } \\
\text { the CES }\end{array}$ & $\begin{array}{l}\text { Acceptable qualitative } \\
\text { frequency of deciding toxic } \\
\text { constituents are present }\end{array}$ & $\begin{array}{l}\text { Acceptable probability of } \\
\text { deciding toxic constituents } \\
\text { are present }\end{array}$ \\
\hline less than 0.01 & almost never (intolerable) & $\leq 1 \%$ \\
0.01 to 0.05 & $\begin{array}{l}\text { rarely } \\
\text { region of decision } \\
\text { indiffererice } \\
0.05 \text { to } 0.1\end{array}$ & $\leq 20 \%$ \\
0.1 to 0.5 & Often \\
0.5 to 1 & almost always & $\geq 80 \%$ \\
1 or more & almost always (tolerable) & $\geq 99 \%$ \\
\hline
\end{tabular}

Table 5-3. Desired Performance for the Toxicity Decision: Systemic Toxicant Constituents.

\begin{tabular}{|l|l|l|}
\hline $\begin{array}{l}\text { Presumed "true" fraction of } \\
\text { the CES }\end{array}$ & $\begin{array}{l}\text { Acceptable qualitative } \\
\text { frequency of deciding toxic } \\
\text { constituents are present }\end{array}$ & $\begin{array}{l}\text { Acceptable probability of } \\
\text { deciding toxic constituents } \\
\text { are present }\end{array}$ \\
\hline less than 0.05 & almost never (intolerable) & $\leq 1 \%$ \\
0.05 to 0.25 & $\begin{array}{l}\text { rarely } \\
\text { region of decision } \\
\text { indifference } \\
0.25 \text { to } 0.5\end{array}$ & $\leq 25 \%$ \\
0.5 to 1 & $\begin{array}{l}\text { almost always } \\
\text { almost always (tolerable) }\end{array}$ & $\geq 99 \%$ \\
more than 1 & al & $\geq 95 \%$ \\
\hline
\end{tabular}


Table 5-4. Desired Performance for the Toxicity Decision: Irritant Constituents.

\begin{tabular}{|l|l|l|}
\hline $\begin{array}{l}\text { Presumed "true" fraction of } \\
\text { the CES }\end{array}$ & $\begin{array}{l}\text { Acceptable qualitative } \\
\text { frequency of deciding toxic } \\
\text { constituents are present }\end{array}$ & $\begin{array}{l}\text { Acceptable probability of } \\
\text { deciding toxic constituents } \\
\text { are present }\end{array}$ \\
\hline $\begin{array}{l}\text { less than } 0.05 \\
0.05 \text { to } 0.25\end{array}$ & $\begin{array}{l}\text { almost never (intolerable) } \\
\text { rarely } \\
\text { region of decision } \\
\text { indifference } \\
\text { almost always }\end{array}$ & $\leq 1 \%$ \\
0.5 to 1 & almost always (tolerable) & $\geq 99 \%$ \\
\hline or more & & $\geq 95 \%$ \\
\hline
\end{tabular}




\subsection{SAMPLING DESIGNS FOR OBTAINING DATA}

The desired performance tables that were identified in Section 5.0 represent the decision maker's tolerance for decision error. These specifications were based on specific assumptions, prior knowledge, and/or expert opinion. Section 6.1 discusses the statistical terminology that relates the desired performance tables to the formal statistical analysis that incorporates the error tolerance specifications.

The statistical analysis presented in Section 6.2 is provided as a retrospective analysis of the previously performed sampling activity (sample job 6).

Section 6.3 contains a summary of the pertinent aspects of sample job 6B. Data from this sampling event will be used to address key flammability and toxicity decisions and to evaluate and select sample acquisition and analytical methods. Also, these data will provide a basis for estimating error terms pertaining to sampling and measurement error components, but will not contain sufficient information for estimating spatial or temporal error components (if they exist). The estimates of error terms that are generated by this study will be used, in a DQO process, to determine the number of samples required in the third sampling event (sample job 7). This third sampling event will be used to estimate spatial and temporal error components.

\subsection{STATISTICAL TERMINOLOGY}

The performance tables in Section 5.0 provide a tool for the decision makers to describe the acceptable probability of making a decision error. The theory behind these tables is based on statistical hypothesis testing, in which the data are used to decide between one condition of the environment (the null hypothesis, $\mathrm{H}_{0}$ ) and an alternative condition (the alternative hypothesis, $\mathrm{H}_{\mathrm{A}}$ ). The null hypothesis is assumed to be true in the absence of strong evidence to the contrary. A decision error occurs when the decision makers are led to believe in one hypothesis when the other is true.

There are two types of decision errors that must be considered. The first type of decision error occurs when the decision makers conclude, based on the data, that $\mathrm{H}_{\mathrm{A}}$ is true when, in fact, $\mathrm{H}_{0}$ is true. This error is sometimes referred to as a false positive, or Type $\mathrm{I}$, error. When the decision makers specify how often they can tolerate making this type of decision error (e.g., 5 out of 100 times), that is often referred to as the Type I error rate, or $\alpha$. The second error occurs when the decision makers conclude, based on available data, that $\mathrm{H}_{0}$ is true when, in fact, $\mathrm{H}_{\mathrm{A}}$ is true. This error is sometimes referred to as false negative, or Type II, error. The Type II error rate, or $\beta$, is the specification of how often the decision maker can tolerate making this type of decision error. 


\subsection{SEMIVOLATILE ORGANIC VAPOR AND AEROSOL SAMPLING}

\subsubsection{Design Assumptions}

The tank headspace is anticipated to be relatively homogeneous. The total study error is anticipated to be primarily a function of analytical error (sampling error is anticipated to be negligible in comparison). Consequently, the design assumptions will focus entirely on the analytical errors. A "total uncertainty" estimate is available from Ligotke et al., 1993, from which statistical measures can be interpreted.

The basic statistical assumptions of the design are that the combined error terms of the statistical model are independent and normally distributed identically with a mean of zero. Consequently, the concentration data are assumed to be independent.

\subsubsection{Select the Appropriate Statistical Test}

It has been determined that if the $\mathrm{FC}_{\mathrm{NPH}} \times 1.5$ is less than $20 \%$ of the temperaturecorrected LFL for the headspace fuel mixture, then intrusive work may be performed. The decision rule was described and justified in Section 4.1. In this section, the hypothesis statement that corresponds to that decision rule will be provided, and the appropriate statistical test will be described.

The hypotheses are distinguished by a comparison of the mean percent $1.5 \times \mathrm{FC}_{\mathrm{NPH}}$ to the action level of $20 \%$ of the $\mathrm{LFL}_{\text {mix }}$. The goal of the statistical testing procedure, as specified through the null and alternative hypotheses, is to determine if there is sufficient evidence in the collected data to reject the hypothesis that the mean percent $1.5 \times \mathrm{FC}_{\mathrm{NPH}}$ is greater than $20 \%$ of the $\mathrm{LFL}_{\text {mix }}$.

Given the design assumptions of independent and identically (normally) distributed events, the appropriate classical statistical test for resolving this problem is a one-sided $t$-test. Consequently, the following design alternatives are generated using a power analysis that corresponds to classical one-sided t-tests. The burden of proof for this one-sided t-test is to demonstrate that the concentration of fuel is small enough that work at the tank should continue (i.e., the burden is to establish the alternative hypothesis). Consequently, the hypotheses can be stated as follows:

$$
\begin{aligned}
& \mathrm{H}_{0}: \quad \text { Mean } 1.5 \times \mathrm{FC}_{\mathrm{NPH}} \geq 20 \% \text { of the } \mathrm{LFL}_{\text {mix }} \\
& \mathrm{H}_{\mathrm{A}}: \quad \text { Mean } 1.5 \times \mathrm{FC}_{\mathrm{NPH}}<20 \% \text { of the } \mathrm{LFL}_{\text {mix }} .
\end{aligned}
$$

The desired performance curve indicates that the specified probability of deciding to stop work at the hypothesis boundary of $20 \%$ of the $L F L_{\text {mix }}$ is 0.90 . Since this corresponds to making the correct decision when the null hypothesis is true, the probability of making an incorrect decision when the null hypothesis is true (i.e., the probability of deciding $\mathrm{H}_{\mathrm{A}}$ when in fact $\mathrm{H}_{0}$ is true), is one minus 0.90 , or 0.10 . Thus, the Type I error rate, or $\alpha$, is 0.1 (in 
other words, the probability of deciding to continue work when, in fact, work should be stopped, is no greater than 0.1 ). Also indicated is that the probability of deciding to stop work at $15 \% \mathrm{LFL}_{\text {mix }}$ should be less than or equal to 0.10 . Since this corresponds to making an incorrect decision when the alternative hypothesis is true, the Type II error rate at $15 \%$ $\mathrm{LFL}_{\text {mix }}$, or $\beta$ at $15 \% \mathrm{LFL}_{\text {mix }}$, is 0.10 (in other words, the probability of stopping work when, in fact, work should continue is no greater than 0.10 ). The region of decision indifference is defined in the desired performance curve as $15 \%$ to $20 \%$ of the $\mathrm{LFL}_{\operatorname{mix}}$.

\subsubsection{Obtain Pertinent Estimates of Uncertainty}

The power analysis used to generate design alternatives requires certain inputs. Some of these inputs are specified in the desired performance curve; i.e., the action level (20\% of the LFL), the width of the region of indifference, and the Type I error rate $^{2}, a$. The goal of the power analysis at the design stage is to determine the sample size for which the remaining constraints specified in the desired performance curve are satisfied. The remaining input that is required to perform the power analysis is an estimate of the standard deviation (or variance) of the normal distribution that is assumed to underlie the distribution of fuel concentrations.

The total uncertainty for NPH concentrations is estimated to be $21 \%$ (Litgotke et al. 1993). This estimate was not presented with a strong statistical basis, but it constitutes the only available estimate of uncertainty for this power analysis. The Litgotke report seems to indicate that the $21 \%$ total uncertainty is used to define an upper (and lower) bound within which a concentration value is expected to lie. If we assume this is the case, then the estimate of standard deviation for NPH concentrations must be back calculated from that value.

In order to account for the limited knowledge regarding the $21 \%$ estimate, a range of possible standard deviation values will be assumed. The approach taken can be regarded as a sensitivity analysis for the design alternatives. If more appropriate statistical measures of the anticipated range of the fuel concentration data can be established, then a more focused design can be implemented that concentrates on those measures.

\subsubsection{Power Analysis of the LFL Decision Rule}

The decision rule can be summarized by the following hypotheses:

$$
\begin{aligned}
& \mathrm{H}_{0}: \quad \text { Mean } 1.5 \times \mathrm{FC}_{\mathrm{NPH}} \geq 20 \% \text { of the } \mathrm{LFL}_{\text {mix }} \\
& \mathrm{H}_{\mathrm{A}}: \quad \text { Mean } 1.5 \times \mathrm{FC}_{\mathrm{NPH}}<20 \% \text { of the } \mathrm{LFL}_{\text {mix }} .
\end{aligned}
$$

\footnotetext{
${ }^{2}$ Equivalently, the power at any point on the desired performance table and its associated power curve can be used in place of $a$, although this adds one step to the mathematical procedure.
} 
The power $(1-\beta)$, as a function of $x$, (the assumed value of $1.5 \times \mathrm{FC}_{\mathrm{NPH}}$ ), is computed using the following equation:

$$
t_{\beta_{x}, n-1}=\frac{0.2-x}{\sqrt{\frac{s^{2}}{n}}}-t_{\alpha, n-1}
$$

where: $\mathrm{n}$ is the sample size,

$t_{\alpha, n-1}$ is the $t$-distribution value with $n-1$ degrees of freedom,

$\mathrm{x}$ is the assumed value of $1.5 \times \mathrm{FC}_{\mathrm{NPH}}$, and

$\mathrm{S}$ is the assumed standard deviation.

The range of values of s used in the power analyses was calculated to be $2 \%$ to $6 \%$ of $1.5 \times \mathrm{FC}_{\mathrm{NPH}}$. Values from within this range of standard deviations were considered in this power analysis. This range was calculated using the following considerations:

For the lower value, the total uncertainty of $21 \%$ was applied as a relative standard deviation for a predicted value of $15 \%$ of $1.5 \times \mathrm{FC}_{\mathrm{NPH}}$, and the sample size of nine was used, resulting in comparison to a t-distribution with seven degrees of freedom for a predicted value ${ }^{3}$. The ensuing standard deviation to be used in this power analysis is approximately 0.02 , or $2 \%$ of $1.5 \times \mathrm{FC}_{\mathrm{NPH}}$.

For the upper value of the standard deviation, the total uncertainty of $21 \%$ was applied as a relative standard deviation for a predicted value of $50 \%$ of $1.5 \times \mathrm{FC}_{\mathrm{NPH}}$, and the large sample size assumption was used, resulting in comparison to a normal distribution. The ensuing standard deviation to be used in this power analysis is approximately 0.06 , or $6 \%$ of $1.5 \times \mathrm{FC}_{\mathrm{NPH}}$.

The values of $15 \%$ and $50 \%$ of $1.5 \times \mathrm{FC}_{\mathrm{NPH}}$ were used because these values were of interest on the previously established desired performance curve. Any number between these two values would result in a standard deviation to be used in the power analysis that falls within the range provided (e.g., if $20 \%$ of $1.5 \times \mathrm{FC}_{\mathrm{NPH}}$ were to be used). Sample sizes of three, six, and nine were considered. The goal of the power analysis in each case is to determine if, based on a Type I error rate of $10 \%$ (as specified in the desired performance curve), the selected sample size is sufficient to satisfy the remaining desired performance curve constraints (i.e., the power at $15 \%$ of $1.5 \times \mathrm{FC}_{\mathrm{NPH}}$ must be no less than 0.9 , and the power at $50 \%$ of $1.5 \times \mathrm{FC}_{\mathrm{NPH}}$ must be no less than 0.99 ).

\footnotetext{
${ }^{3}$ The appropriate degrees of freedom to use in relation to predicted values is $n-2$. This should not be confused with the $n-1$ degrees of freedom that is appropriate for the ensuing power analysis for a one-sided t-test.
} 
Accordingly, the power analysis was performed for standard deviation values between 0.02 and 0.06 with increments of 0.01 . For a standard deviation of 0.02 , all three choices for sample sizes (three, six, and nine) are sufficient to fully satisfy the remaining constraints of the desired performance curve. The situation changes as the standard deviation is increased until, at a standard deviation of 0.06 , nine samples are not quite adequate to fully satisfy the constraints of the desired performance curve. The following paragraphs provide more detailed breakdowns for each choice of standard deviation used:

For standard deviations of 0.03 and 0.04 , three samples are not sufficient to fully satisfy the remaining constraints of the desired performance curve, whereas both six and nine samples are sufficient. For a standard deviation of .03 , if the observed mean $1.5 \times \mathrm{FC}_{\mathrm{NPH}}$ concentration based on three sample observations is less than approximately $12 \%$ of the $\mathrm{LFL}_{\text {mix }}$, then the data will still be sufficient to support the decision. Alternatively, if the observed mean $1.5 \times \mathrm{FC}_{\mathrm{NPH}}$ concentration based on three sample observations is between $12 \%$ and $15 \%$ of the $\mathrm{LFL}_{\text {mix }}$, then the probability of incorrectly deciding to stop work may be as high as 0.21 (calculated as 1 - power at $15 \%$ of $1.5 \times \mathrm{FC}_{\mathrm{NPH}}$ ). Similarly, for a standard deviation of .04 , if the observed mean $1.5 \times \mathrm{FC}_{\mathrm{NPH}}$ concentration based on three sample observations is less than approximately $10 \%$ of the $\mathrm{LFL}_{\text {mix }}$, then the data will still be sufficient to support the decision. Alternatively, if the observed mean $1.5 \times \mathrm{FC}_{\mathrm{NPH}}$ concentration based on three sample observations is between $10 \%$ and $15 \%$ of the $\mathrm{LFL}_{\text {mix }}$, then the probability of incorrectly deciding to stop work may be as high as 0.4 .

For a standard deviation of 0.05 , neither three nor six samples are sufficient to fully satisfy the constraints, whereas nine samples are sufficient. For a sample size of three, if the observed mean $1.5 \times \mathrm{FC}_{\mathrm{NPH}}$ concentration is less than approximately $9 \%$ of the $\mathrm{LFL}_{\text {mix }}$, then the data will still be sufficient to support the decision.

Alternatively, if the observed mean $1.5 \times \mathrm{FC}_{\mathrm{NPH}}$ concentration based on three sample observations is between $9 \%$ and $15 \%$ of the $\mathrm{LFL}_{\text {mix }}$, then the probability of incorrectly deciding to stop work may be as high as 0.55 . Similarly, for a sample size of six, if the observed mean $1.5 \times \mathrm{FC}_{\mathrm{NPH}}$ concentration is less than approximately $13 \%$ of the $\mathrm{LFL}_{\text {mix }}$, then the data will still be sufficient to support the decision. Alternatively, if the observed mean $1.5 \times \mathrm{FC}_{\mathrm{NPH}}$ concentration based on six sample observations is between $13 \%$ and $15 \%$ of the $\mathrm{LFL}_{\text {mix }}$, then the probability of incorrectly deciding to stop work may be as high as 0.19 .

Finally, for a standard deviation of 0.06 , nine samples are not sufficient to satisfy all the constraints of the spe -ified desired performance curve. For a sample size of three, if the observed mean $1.5 \times \mathrm{FC}_{\mathrm{NPH}}$ concentration is less than approximately $7 \%$ of the $\mathrm{LFL}_{\text {mix }}$, then the data will still be sufficient to support the decision.

Alternatively, if the observed mean $1.5 \times \mathrm{FC}_{\mathrm{NPH}}$ concentration based on three sample observations is between $7 \%$ and $15 \%$ of the $\mathrm{LFL}_{\text {mix }}$, then the probability of incorrectly deciding to stop work may be as high as 0.65 . Similarly, for a sample size of six, if the observed mean $1.5 \times \mathrm{FC}_{\mathrm{NPH}}$ concentration is less than approximately $12 \%$ of the $\mathrm{LFL}_{\text {mix }}$, then the data will still be sufficient to support the decision. Alternatively, if 
the observed mean $1.5 \times \mathrm{FC}_{\mathrm{NPH}}$ concentration based on six sample observations is between $12 \%$ and $15 \%$ of the $\mathrm{LFL}_{\text {mix }}$, then the probability of incorrectly deciding to stop work may be as high as 0.3 . Finally, for a sample size of nine, if the observed mean $1.5 \times \mathrm{FC}_{\mathrm{NPH}}$ concentration is less than approximately $14 \%$ of the $\mathrm{LFL}_{\text {mix }}$, then the data will still be sufficient to support the decision. Alternatively, if the observed mean $1.5 \times \mathrm{FC}_{\mathrm{NPH}}$ concentration based on six sample observations is between $14 \%$ and $15 \%$ of the $\mathrm{LFL}_{\text {mix }}$, then the probability of incorrectly deciding to stop work may be as high as 0.15 .

The five power analyses are presented in tabular form, with Tables 6-1 through 6-5 corresponding, in order, to assumptions for the standard deviation of 0.02 through 0.06 . The bold numbers correspond to desired power specifications that were not met by the assumed standard deviation and sample size.

Once the data is available from the semivolatile organic vapor and aerosol sampling event, a power analysis based on the observed data will be performed to enable comparison to the desired performance curve constraints. This evaluation of the performance of the design will help to determine if the decision error tolerances have been satisfied at all points, and, more particularly, if the observed mean $1.5 \times \mathrm{FC}_{\mathrm{NPH}}$ concentration corresponds to an observed power that does not violate any of the constraints of the desired performance curve. For example, if, as anticipated, the observed mean concentration is comparatively small (around 7\%), then the constraints of the desired performance curve are satisfied for as few as three samples for all of the standard deviation values considered.

When evaluating the quality of the data gathered during the flammability sampling, it will be important to assess the total analytical and sampling uncertainty of the design. Because the survey was implemented, the data is now available to assess the assumptions regarding standard deviation, to assess other design assumptions such as the 1.5 factor for $\mathrm{FC}_{\mathrm{NPH}}$, and to identify fuel components other than NPH. The quality assurance data collected during the laboratory analysis as it relates to desorption efficiency is crucial. Desorption efficiency is expected to be the largest contributor to NPH measurements.

Table 6-1. Desired and Achieved Power Given a Standard Deviation of 0.02.

\begin{tabular}{|c|c|c|c|c|}
\hline \multirow{2}{*}{ True Value } & \multirow{2}{*}{ Desired Power } & \multicolumn{3}{|c|}{ Power for a number of analyses (N) } \\
\cline { 3 - 5 } & & $\mathrm{N}=3$ & $\mathrm{~N}=6$ & $\mathrm{~N}=9$ \\
\hline 0.15 & $\geq 0.90$ & 0.933 & 0.997 & 1.000 \\
\hline 0.20 & $=0.10$ & 0.100 & 0.100 & 0.100 \\
\hline 0.50 & $\leq 0.01$ & 0.001 & 0.000 & 0.000 \\
\hline
\end{tabular}


Table 6-2. Desired and Achieved Power Given a Standard Deviation of 0.03 .

\begin{tabular}{|c|c|c|c|c|}
\hline \multirow{2}{*}{ True Value } & \multirow{2}{*}{ Desired Power } & \multicolumn{3}{|c|}{ Power for a number of analyses $(\mathrm{N})$} \\
\cline { 3 - 5 } & & $\mathbf{N = 3}$ & $\mathrm{N}=6$ & $\mathrm{~N}=9$ \\
\hline 0.15 & $\geq 0.90$ & $\mathbf{0 . 7 8 9}$ & 0.976 & 0.997 \\
\hline 0.20 & $=0.10$ & 0.100 & 0.100 & 0.100 \\
\hline 0.50 & $\leq 0.01$ & 0.001 & 0.000 & 0.000 \\
\hline
\end{tabular}

Table 6-3. Desired and Achieved Power Given a Standard Deviation of 0.04.

\begin{tabular}{|c|c|c|c|c|}
\hline \multirow{2}{*}{ True Value } & \multirow{2}{*}{ Desired Power } & \multicolumn{3}{|c|}{ Power for a number of analyses $(\mathrm{N})$} \\
\cline { 3 - 5 } & & $\mathbf{N}=\mathbf{3}$ & $\mathbf{N}=6$ & $\mathbf{N}=9$ \\
\hline 0.15 & $\geq 0.90$ & $\mathbf{0 . 5 9 7}$ & 0.913 & 0.977 \\
\hline 0.20 & $=0.10$ & 0.100 & 0.100 & 0.100 \\
\hline 0.50 & $\leq 0.01$ & 0.002 & 0.000 & 0.000 \\
\hline
\end{tabular}

Table 6-4. Desired and Achieved Power Given a Standard Deviation of 0.05.

\begin{tabular}{|c|c|c|c|c|}
\hline \multirow{2}{*}{ True Value } & \multirow{2}{*}{ Desired Power } & \multicolumn{3}{|c|}{ Power for a number of analyses (N) } \\
\cline { 3 - 5 } & & $\mathbf{N = 3}$ & $\mathbf{N = 6}$ & $\mathbf{N}=9$ \\
\hline 0.15 & $\geq 0.90$ & $\mathbf{0 . 4 4 6}$ & $\mathbf{0 . 8 1 3}$ & 0.926 \\
\hline 0.20 & $=0.10$ & 0.100 & 0.100 & 0.100 \\
\hline 0.50 & $\leq 0.01$ & 0.003 & 0.000 & 0.000 \\
\hline
\end{tabular}

Table 6-5. Desired and Achieved Power Given a Standard Deviation of 0.06 .

\begin{tabular}{|c|c|c|c|c|}
\hline \multirow{2}{*}{ True Value } & \multirow{2}{*}{ Desired Power } & \multicolumn{3}{|c|}{ Power for a number of analyses $(\mathrm{N})$} \\
\cline { 3 - 5 } & & $\mathbf{N = 3}$ & $\mathbf{N}=\mathbf{6}$ & $\mathbf{N = 9}$ \\
\hline 0.15 & $\geq 0.90$ & $\mathbf{0 . 3 5 1}$ & $\mathbf{0 . 7 0 2}$ & $\mathbf{0 . 8 4 9}$ \\
\hline 0.20 & $=0.10$ & 0.100 & 0.100 & 0.100 \\
\hline 0.50 & $\leq 0.01$ & 0.004 & 0.000 & 0.000 \\
\hline
\end{tabular}




\subsection{HEATED SINGLE TUBE SAMPLE JOB}

\subsubsection{Design Assumptions}

For this sample job, the flammability and toxicity decision rules will both be addressed. However, the assumptions that applied to the flammability decision for the semivolatile organic and aerosol sample job still apply to the flammability and toxicity decision rules for this sample job. The two assumptions of importance are that the headspace contents are anticipated to be relatively homogeneous, and that the total study error is approximately equal to measurement error. The discussion in Section 6.2.1 applies to this sample job.

\subsubsection{Select the Appropriate Statistical Test}

The hypotheses and statistical tests for flammability that were used for the semivolatile organic vapor and aerosol sampling (sample job 6) in Section 6.2.2 are applicable to the flammability decision rule for this sample job except that the fuel content of the headspace is based on the combined concentrations of all important flammable constituents.

The hypotheses for the toxicity decision rule for known or suspected human carcinogens are distinguished by a comparison of the average concentrations of carcinogens (this includes teratogens and mutagens) to the action level ( $0.1 \times$ the CES for carcinogens). The goal of the statistical testing procedure is to determine if there is sufficient evidence in the collected data to reject the hypothesis that the average concentration of carcinogens is greater than the action level. The appropriate classical statistical test for resolving this problem is a one-sided t-test. The hypotheses can be stated as follows:

\section{$\mathrm{H}_{0}$ : $\quad$ Mean concentration of each carcinogen $\geq 0.1 \times \mathrm{CES}$ \\ $\mathrm{H}_{\mathrm{A}}$ : Mean concentration of each carcinogen $<0.1 \times$ CES.}

The desired pertormance curve (Table 5-2) indicates that the specified probability of deciding toxic constituents are present at the hypothesis boundary of $0.10 \times$ CES is 0.80 . Since this corresponds to making the correct decision when the null hypothesis is true, the probability of making an incorrect decision when the null hypothesis is true (i.e., the probability of deciding $\mathrm{H}_{A}$ when in fact $\mathrm{H}_{0}$ is true) is one minus 0.80 , or 0.20 . Thus, the Type I error rate, or $\alpha$, is 0.20 (in other words, the probability of deciding that toxic constituents are not present when, ir fact, they are, is no greater than 0.20 ). Also indicated is that the probability of deciding to stop work at $0.05 \times$ the CES should be less than or equal to 0.20 . Since this corresponds to making an incorrect decision when the alternative hypothesis is true, the Type II error rate at $0.05 \times$ CES, or $\beta$ at $0.05 \times$ CES, is 0.20 (in other words, the probability of deciding that toxic constituents are present when, in fact, they are not, is no greater than 0.20 ). The region of decision indifference is defined in the desired performance curve at 0.05 to $0.10 \times$ CES. 
The hypotheses for the toxicity decision rule for systemic toxins and for irritants are distinguished by a comparison of the average concentrations of systemic toxins or irritants to the action level of $0.5 \times$ CES. The appropriate classical statistical test for resolving these problems is a one-sided t-test. The hypotheses can be stated as follows:

$\mathrm{H}_{0}$ : $\quad$ Mean concentration of each systemic toxin $\geq 0.50 \times$ CES

$\mathrm{H}_{\mathrm{A}}$ : Mean concentration of each systemic toxin $<0.50 \times$ CES

and

$\mathrm{H}_{0}$ : Mean concentration of each irritant $\geq 0.50 \times \mathrm{CES}$

$\mathrm{H}_{\mathrm{A}}$ : Mean concentration of each irritant $<0.50 \times$ CES.

The desired performance curves for these decisions are found in Tables 5-3 and 5-4. Using the same discussion as for carcinogens, the Type I error rate, or $\alpha$, for these constituents is 0.05 . The Type II error rate at $0.25 \times \mathrm{CES}$, or $\beta$ at $0.25 \times \mathrm{CES}$, is 0.25 . The region of indifference is between 0.25 and $0.5 \times$ CES.

\subsubsection{Obtain Pertinent Estimates of Uncertainty}

No estimates of uncertainty were available for the measurement error for the flammability. If one could assume that the estimate of uncertainty for $\mathrm{FC}_{\mathrm{NPH}}$ is equivalent to the estimate of uncertainty for later fuel content estimates, then the estimates of uncertainty that were used for the flammability decision for the semivolatile vapor and aerosol sample job may be applicable for the flammability decision for the heated tube sample job. See the discussion in Section 6.1.3 for that particular estimate of uncertainty. However, this assumption is probably not valid.

Estimates of uncertainty for the toxicity decision rule do not exist at this time. Engineering judgement estimates of the important sources of uncertainty could be obtained, but none of the estimates can be directly tied to observed data.

\subsubsection{Power Analysis}

No power analyses were performed for the flammability and toxicity decision rules for the heated tube sampling event because no prior estimates of uncertainty were available. We also recognize that the data collected in the semivolatile vapor and aerosol sample jobs and in the heated tube sample jobs will provide the basis for sample job 7. These earlier sample jobs are intended to provide the information needed to appropriately gather data for sample job 7. A retrospective power analysis could provide a useful look at the achievable probabilities of decision error if estimates of uncertainty were available. However, with no previous estimate of uncertainty for either decision rule, there is not much benefit in assessing the power analysis at this time. 
In summary, the information that we expect to have at the completion of the semivolatile vapor and aerosol and heated tube sample jobs are as follows:

1) The chemical characterization and concentration of C-103 headspace gasses

2) The estimates of analyte recovery from methods and chemical standards of analytical procedures

3) Data that can be used for the identification and concentration estimates for analytes of concern for CES

4) Data that is available to quantify the spatial and analytical variations which in turn can be used to

- conduct a retrospective evaluation of the adequacy of sample jobs 6 and $6 \mathrm{~B}$

- design the April sampling job (sample job 7).

Based on all of the above inputs, the sample and analysis plan for sample job 7 can be appropriately investigated for a retrospective investigation of achievable decision errors. Sample job 7 will not be discussed further in this document, but will be evaluated upon receipt of data from the semivolatile vapor and aerosol and heated tube sample jobs. 


\subsection{REFERENCES}

29 CFR 1910, 1991, "Occupational Safety and Health Standards," Code of Federal Regulations, as amended.

Carothers, K.G., 1988, Tank 103-C Transaction History - Post January 1976, (internal memorandum 13331-88-600 to Distribution, September 22), Westinghouse Hanford Company, Richland, Washington.

Christensen, R. F., 1993, Engineering Assessment of the Aerosol and Vapor Flammability in 241-C-103, (letter 9303779 to President, Westinghouse Hanford Company, May 18), Department of Energy, Richland Field Office, Richland, Washington.

Engelmann, R. H., 1993, Environmental Assessment: Tank 241-C-103 Organic Vapor and Liquid Characterization and Supporting Activities, Hanford Site, Richland, Washington, (internal memorandum 88800-93-048 Rev. 2, to G. M. Christensen, June 10), Westinghouse Hanford Company, Richland, Washington.

Hanlon, B.M., 1994, Tank Farm Surveillance and Waste Status Summary Report for October 1993, WHC-EP-0182-67, Westinghouse Hanford Company, Richland, Washington.

Huckaby, J.L. and S.D. Estey, 1992, An Engineering Assessment of the Aerosol and Vapor Flammability in 241-C-103, WHC-SD-WM-ER-181, Westinghouse Hanford Company, Richiand, Washington.

Huckaby, J. L., 1993, Engineering Work Plan for Aerosol and Vapor Sample Collection in Tank 241-C-103, WHC-SD-WM-WP-198, Rev. 0, Westinghouse Hanford Company, Richland, Washington.

Jungfleisch, F.M., 1987, Historical Perspectives of Wastes in Tank 241-C-103, (internal memorandum 133213-87-129 to K.G. Carothers, November 6), Westinghouse Hanford Company, Richland, Washington.

Ligotke, M. W., T. R. Clauss, J. L. Huckaby, G. W. Dennis, R. B. Lucke, S. C. Goheen, Aerosol and Vapor Characterization of Tank 241-C-103: Flammability Assessment Sampling System and Method Validation, PNL-8875, Pacific Northwest Laboratory, Richland, Washington.

Michael, D.I., D. Neptune, R. Ryti, P. Black, J. Scott, B. Pulsipher, 1993, Tank Waste Remediation System Data Quality Objectives Process Guidance: Requirements, Style and Content, Neptune and Company, Los Alamos, New Mexico. 
O'Dell, C. S., 1993, Comments on "An Engineering Assessment of the Aerosol and Vapor Flammability in 241-C-103, "WHC-SD-WM-ER-181, Rev. O, Dated December 14, 1992, (internal memorandum to R. F. Christensen, May 3), U. S. Department of Energy, Richland Field Office, Richlarid, Washington.

Osborne, 1992, Program Plan for the Resolution of Tank Vapor Issues, WHC-EP-0562, Westinghouse Hanford Company, Richland, Washington.

Strachan, D.M., W.W. Schultz, and D.A. Reynolds, 1993, Hanford Site Organic Waste Tanks: History, Waste Properties and Scientific Issues, PNL-8473, Pacific Northwest Laboratory, Richland, Washington.

Trent, G.J., 1990, Flammability Potential of Tank 103-C Headspace Vapors, (internal memorandum 82331-0-312.8 to G. L. Dunford, July 24), Westinghouse Hanford Company, Richland, Washington.

USEPA, 1993, Guidance for Planning Data Collection in Support of Environmental Decision Making Using the Data Quality Objectives Process, EPA QA/G4, Interim Final, U. S. Environmental Protection Agency, Washington, D.C.

Zabetakis, M.G., 1965, Flammability Characteristics of Combustible Gases and Vapors, Bureau of Mines Bulletin 627, U. S. Department of the Interior, Washington, D.C. 


\section{DISTRIBUTION}

Number of copies

\section{OFFSITE}

4

U.S. Department of Energy

Trevion II, EM-362

19901 Germantown Road

Germantown, MD 20874-1290

Charles O'Dell (3)

Ken Lang

1

U.S. Department of Energy

1000 Independence Ave SW

EM-35

Washington, D.C. 20585

M. Corn

1

Charles S. Abrams

1987 Virginia

Idaho Falls, ID 83404

Fred N. Carlson

6965 North 5th West

Idaho Falls, ID 83401

1 Donald T. Oakley

555 Quince Orchard Road

Gaithersburg, MD 20878

$1 \quad$ Air Products and Chemicals

7201 Hamilton Blvd

Allentown, PA 18195-1501

George E. Schmauch

1

Harvard School of Public Health

665 Huntington Ave

Bldg 1, Rm G-1

Boston, MA 02115

Melvin W. First 


\section{DISTRIBUTION (continued)}

\section{OFFSITE}

MIT/Dept of Nuclear Eng.

77 Massachusetts Ave.

Room 24-102

Cambridge, MA 02193

Mujid S. Kazimi

2

Neptune and Company

P.O. Box 10

Los Alamos, NM 87544

D. Neptune

D. Michael

1 Northwest Instrument Systems, Inc.

3100 George Washington Way

Richland, WA 99352

Michael S. Story

1 Science Applications International Corporation 12850 Middlebrook Road

Trevion I, Suite 300

Germantown, MD 20874

Ray S. Daniels

\section{ONSITE}

11 U.S. Department of Energy, Richland Field Office

S. O. Branch

R. F. Christensen (8)

R. E. Gerton

Public Reading Room
R3-72

A4-02

A4-02

A1-65 


\section{DISTRIBUTION (continued)}

\section{ONSITE}

Pacific Northwest Laboratory

C. M. Anderson

$\mathrm{K} 7-34$

R. M. Bean

P8-08

S. C. Goheen

P8-08

D. D. Mahlum

$\mathrm{P} 7-56$

B. A. Pulsipher

K7-34

J. L. Scott

P7-35

J. Y. Young

K4-16

PNL Technical Files

K1-11

36 Westinghouse Hanford Company

W. T. Alumkal

R2-52

H. Babad

R2-78

M. L. Bell

T6-16

R. B. Conrad

H5-09

C. DeFigh-Price (3)

B4-55

J. M. Grigsby

H5-32

E. R. Hewitt

R3-01

J. L. Huckaby (10)

R2-78

R. A. Huckfeldt

R3-54

M. N. Islam

R3-08

J. L. Lee

R2-36

J. R. Mobley

R2-18

D. J. Newland

R2-36

J. W. Osborne

R2-78

M. A. Payne

R2-50

T. P. Rudolph

R3-54

C. D. Suydam

S3-30

D. A. Turner

R2-78

Document Processing and Distribution (2) L8-15

Central Files

L8-04

Information Release Administration (3)

A2-24

TFIC

R1-20 

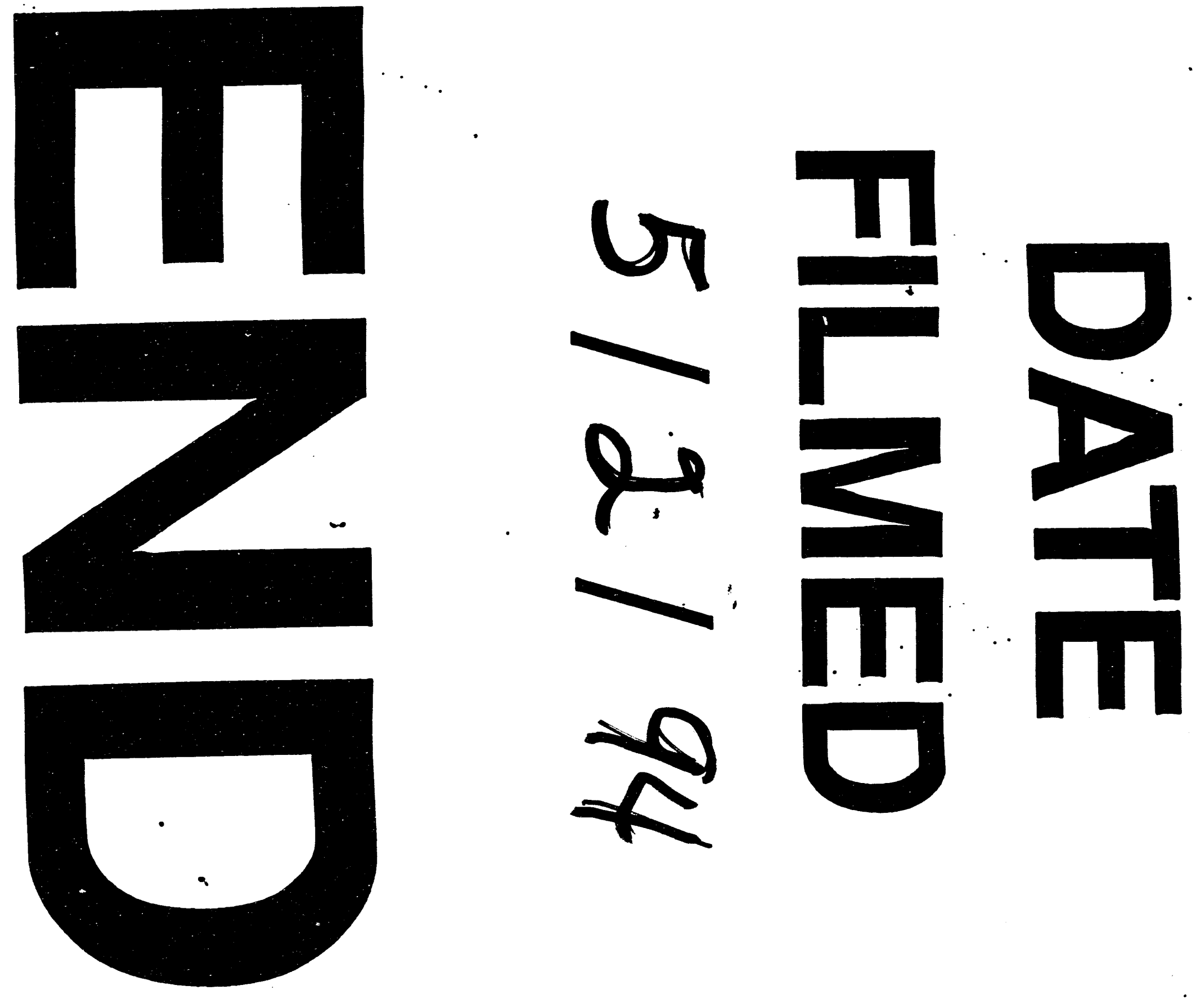
